Article

\title{
Establishing Relationships between Drought Indices and Wildfire Danger Outputs: A Test Case for the California-Nevada Drought Early Warning System
}

\author{
Daniel J. McEvoy 1,2, ${ }^{\text {, Mike Hobbins }}{ }^{3,4}$, Timothy J. Brown ${ }^{1,2}$, Kristin VanderMolen ${ }^{1,2}$, \\ Tamara Wall ${ }^{1,2}$, Justin L. Huntington ${ }^{2,5}$ and Mark Svoboda ${ }^{6}$ (D) \\ 1 Division of Atmospheric Sciences, Desert Research Institute, 2215 Raggio Parkway, Reno, NV 89512, USA; \\ tim.brown@dri.edu (T.J.B.); kristin.vandermolen@dri.edu (K.V.); tamara.wall@dri.edu (T.W.) \\ 2 Western Regional Climate Center, 2215 Raggio Parkway, Reno, NV 89512, USA; justin.huntington@dri.edu \\ 3 Cooperative Institute for Research in Environmental Sciences, University of Colorado Boulder, 216 UCB, \\ Boulder, CO 80309, USA; mike.hobbins@noaa.gov \\ 4 Physical Sciences Division, NOAA/Earth System Research Laboratory/Physical Sciences Division, \\ 325 Broadway, Boulder, CO 80305-3328, USA \\ 5 Division of Hydrologic Sciences, Desert Research Institute, 2215 Raggio Parkway, Reno, NV 89512, USA \\ 6 School of Natural Resources, National Drought Mitigation Center, University of Nebraska-Lincoln, \\ 3310 Holdrege Street, Lincoln, NE 68583-0961, USA; msvoboda2@unl.edu \\ * Correspondence: mcevoy@dri.edu; Tel.: +1-775-673-7682
}

Received: 15 February 2019; Accepted: 1 April 2019; Published: 5 April 2019

\begin{abstract}
Relationships between drought indices and fire danger outputs are examined to (1) incorporate fire risk information into the National Integrated Drought Information System California-Nevada Drought Early Warning System and (2) provide a baseline analysis for application of drought indices into a fire risk management framework. We analyzed four drought indices that incorporate precipitation and evaporative demand $\left(\mathrm{E}_{0}\right)$ and three fire indices that reflect fuel moisture and potential fire intensity. Seasonally averaged fire danger outputs were most strongly correlated to multi-scalar drought indices that use $\mathrm{E}_{0}$ (the Evaporative Demand Drought Index (EDDI) and the Standardized Precipitation Evapotranspiration Index (SPEI)) at approximately annual time scales that reflect buildup of antecedent drought conditions. Results indicate that EDDI and SPEI can inform seasonal fire potential outlooks at the beginning of summer. An $\mathrm{E}_{0}$ decomposition case study of conditions prior to the Tubbs Fire in Northern California indicate high $\mathrm{E}_{0}$ (97th percentile) driven predominantly by low humidity signaled increased fire potential several days before the start of the fire. Initial use of EDDI by fire management groups during summer and fall 2018 highlights several value-added applications, including seasonal fire potential outlooks, funding fire severity level requests, and assessing set-up conditions prior to large, explosive fire cases.
\end{abstract}

Keywords: drought; wildfire; drought index; fuel moisture; California; Nevada; evaporative demand

\section{Introduction}

Wildfire activity is directly linked to variations in weather and climate [1,2], and a number of studies have examined the link between drought indicators and wildfire occurrence in the western U.S. [3-5]. A drying trend has been observed in the southwestern U.S. over the past several decades [6,7] and instrumental records show the 2012-2015 period as one of the driest in California-Nevada (CA-NV) historical records [8-10] with compounding severe drought impacts driven by elevated temperatures resulting from climate change [11,12]. Western U.S. wildfires are 
becoming larger in recent decades in terms of area burned [7], with 15 of the top 20 largest wildfires in California's history occurring in the 21st century [13].

A requirement for large and destructive wildfires is abundant masses of fuels (dead and live vegetation) that are sufficiently dry to burn at high intensity and spread quickly. This is the most prominent link between drought and wildfire-drying at both climate and weather time scales critically affects the amount of moisture contained in available fuels. At climate time scales (i.e., one month to several years) meteorological drought can be considered the primary factor in drying of fuels through accumulated precipitation deficits and a simple lack of available water to support healthy vegetation in the plant water balance. These drying effects become more severe and accelerated during periods of above average temperatures when increased evapotranspiration (ET) leads to increased vegetative stress. A Mediterranean climate prevails over CA-NV (this is more pronounced in California) with a distinct dry season for about half of the year. This seasonal pattern leads to a climatological drying of fuels and high fire potential nearly every year that peaks during late summer into early fall. Climate enables fire and weather drives fire. Persistent hot, dry, and windy conditions clearly increase fire potential, but even short-term (1-2 weeks) periods of anomalous high temperature and low atmospheric moisture can lead to flash drying of fuels and a rapid increase in fire potential. The climate and weather patterns of the region, both California and Nevada are fire-prone environments with substantial wildland-urban interface communities, highlight the value of having an improved understanding of the relationships between drought and wildfire; more specifically, an understanding of how drought indices are related to fire danger outputs, both used by the public and fire management.

During the California dry season, lack of precipitation is a dominant factor for fuel drying, but fire weather (daily time scales out to patterns that can persist for several weeks) is more important for driving severe and extreme fire. Hot temperature, low humidity, and near-surface high wind speed are key fire weather variables. These elements can lead to flash drying of fuels early or late in the dry season and add stress to larger live fuels (i.e., large brush and timber). Impacts from short-term drying conditions and extended drought can have acute effects on fire growth due to the reduction in fuel moisture, devolving into extreme fire conditions that can be deadly [14]. Yet little research has been conducted on how drought information relates to fuel moisture and other measures of fire danger.

Many drought indices are driven by standard climate variables of precipitation and/or temperature, but more recent developments include variables that express conditions at the land surface-atmosphere interface, such as vegetation health [15], soil moisture [16,17], actual ET [18], and evaporative demand $\left(E_{0}\right)[19-21]$. These biophysical variables have also shown stronger correlations to forested area burned in the western U.S. compared to just temperature or precipitation, and the strongest relationships in northern California and the Southwest were found using $\mathrm{E}_{0}$ [22]. Physically based $\mathrm{E}_{0}$ methods use temperature, humidity, wind speed, and solar radiation: These are also the key variables used for computing national fire danger outputs.

This study examines connections between drought indices, based on standard and biophysical climate variables, and National Fire Danger Rating System outputs. One relevant use of this information is to help inform inputs for product generation such as the Predictive Services' [23] significant fire potential outlooks that are currently issued at both weather and seasonal time scales. We chose to relate drought indices to fire danger outputs instead of actual fire occurrence because fire danger, representing the potential fire as related to climate and weather, is used daily by all fire management groups for planning purposes, and the public has familiarity with fire danger such as via roadside Smokey the Bear signs.

A correlation analysis was conducted using drought and fire danger outputs in CA-NV using wildland fire-management regions to answer several research questions:

- Which drought index, or combination of indices, is most strongly related to fire danger outputs?

- For multi-scalar drought indices, what time scales relate best to fire danger outputs?

- Do strong correlations exist at lag times useful for predictive purposes of fire potential? 
An overarching question is what are the relationships between common drought indices and National Fire Danger Rating System (NFDRS) outputs to help understand what drought indices might complement NFDRS, or even be integrated into NFDRS. Further, as climate is an enabler of fire, understanding the correlation between longer monthly to seasonal scale drought indices and shorter-term NFDRS outputs allows for a more complete picture of fire potential from short-term to seasonal scales.

Additionally, in this paper, a case study is described using a recent large and destructive wildfire in northern California to highlight the potential use of $\mathrm{E}_{0}$-decomposition methods to identify the drivers and early onset of increased fire potential. This provides for examining the primary $\mathrm{E}_{0}$ factors most influencing fuels conditions prior to an ignition event.

\section{Study Area}

The study was conducted over California and Nevada in the western U.S. Recently, the National Integrated Drought Information System (NIDIS) began development of the California-Nevada Drought Early Warning System (CA-NV DEWS) [24] with a goal of providing information on drought and wildfire to CA-NV DEWS stakeholders and the wildland fire management community. Predictive Service Areas (PSAs), spatial boundaries used by Predictive Services for wildland fire activity monitoring and forecasting, were used as spatial averaging domains for all indices.

Figure 1 shows the seasonal distribution of the total number of large wildfires (>1000 acres) for each PSA over the period 1984-2015. Fire count data is from the Monitoring Trends in Burn Severity database [25]. A clear seasonal cycle in fire can be seen with most fires occurring during the summer (the climatological dry season). However, large wildfires can occur during any season, particularly in California. As a case in point: Two extreme wildfire events occurred during October and December of 2017 [26,27] and two more during November of 2018 [13]. These events emphasize the need to conduct fire-related studies during all periods of the year, and not just the dry season.

Total \# Large Wildfires (1984-2015)
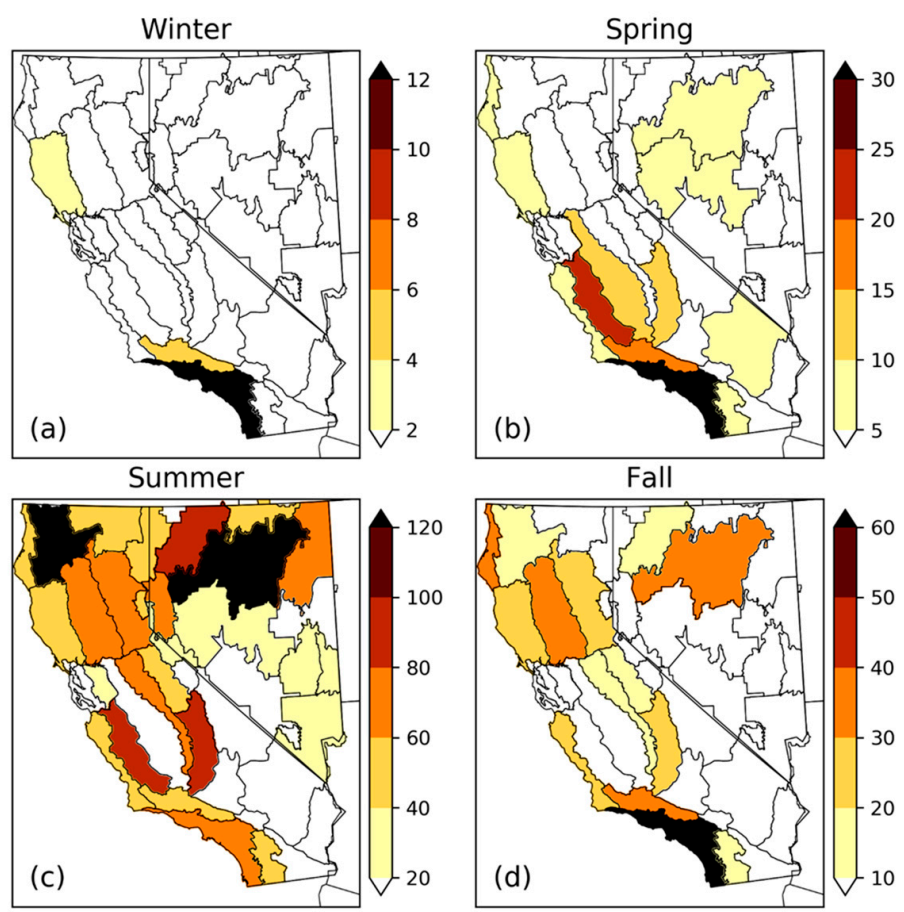

Figure 1. Total number of large wildfires (>1000 acres burned) for (a) winter, (b) spring, (c) summer, and (d) fall across the period 1984-2015 for each Predictive Service Area (PSA) in California and Nevada. Note the scale changes for each season. 


\section{Data and Methods}

\subsection{Climate Data}

All derived indices in this study were calculated using the University of Idaho's gridded meteorological data (gridMET) [28]. The gridMET data cover the contiguous U.S. at a 4-km spatial resolution and daily temporal resolution. For this study, the 1979-2015 period was used for the correlation analysis and 2017 data were used for the case study. gridMET has recently become a popular tool for fire-related studies due to its high space-time resolution and availability of additional fire-related variables, including humidity, wind speed, and solar radiation.

\subsection{Drought Indices}

Four established drought indices were used in this study. The Palmer Drought Severity Index (PDSI) [29] has historically been one of the most heavily used indices for drought monitoring. The PDSI relies on precipitation and $\mathrm{E}_{0}$ as inputs to a simplified soil-water balance and is considered a good indicator of soil moisture at time scales of about 9-12 months or longer [19]. PDSI calculations are made as part of the gridMET archive and were downloaded for the period 1979-2015. Traditionally, PDSI is calculated monthly, but gridMET PDSI uses a modified formula to estimate values at 10-day time steps [30]. The American Society for Civil Engineers standardized reference ET [31] computed from temperature, wind speed, humidity, and solar radiation was used for $\mathrm{E}_{0}$ in the gridMET PDSI, and all other $\mathrm{E}_{0}$-based drought indices described below.

The Standardized Precipitation Index (SPI) [32] is based only on precipitation and was the first drought index to allow for drought time scales to be defined by the user. The Standardized Precipitation Evapotranspiration Index (SPEI) [19] is a variation of the SPI that incorporates $E_{0}$ and examines the accumulated difference between precipitation and $E_{0}$. The Evaporative Demand Drought Index (EDDI) $[20,21]$ looks only at $\mathrm{E}_{0}$, which has been shown to signal the onset of rapid drying and flash drought before other indicators such as precipitation, soil moisture, and actual ET [21,33,34]. A key advantage of multiscalar drought indices is the ability to link different durations of drought to other natural processes such as hydroclimatic variability [35-37], ecological indicators [38], and wildland fire fuel moisture. Precipitation and $E_{0}$ data were based on gridMET for our study period, and SPI, SPEI, and EDDI were computed using a non-parametric plotting position-based probability approach $[39,40]$. Seventeen drought index time scales were examined in this study: 1- to 3-week, 1- to 12-, 15-, and 18-month.

\subsection{Fire Danger Outputs}

Fire-management agencies rely heavily on National Fire Danger Rating System outputs (NFDRS) [41] for operational monitoring and wildland fire assessments. The following three NFDRS indices were used in this study: 100-h fuel moisture, 1000-h fuel moisture, and the Energy Release Component (ERC). These indices are computed using the fire weather variables of precipitation, temperature, humidity, solar radiation, and wind speed. The 100- and 1000-h fuel moisture indices estimate dead fuel moisture at $2.5-7.6 \mathrm{~cm}$ and $7.6-20.3 \mathrm{~cm}$ diameters, respectively, while the ERC is an energy measure of the combined effects of fire intensity and dead and live fuel moisture [41]. All fire danger outputs are computed as part of the gridMET archive and were downloaded for the study period.

\subsection{Correlation Analysis}

A correlation analysis was performed to establish basic relationships between fire danger outputs and drought indices. For each PSA in CA-NV, fire danger outputs were first averaged spatially across the entire PSA and then averaged temporally over each season in each year, resulting in four 37-year time series for each index: Winter (December-February), spring (March-May), summer (June-August), and fall (September-November). For drought indices, PDSI and gridMET precipitation and $\mathrm{E}_{0}$ were 
averaged over each PSA. Spatially averaged gridMET variables were then used to compute SPI, SPEI, and EDDI time series at 17 different time scales ranging from 1-week to 18-month. A Pearson correlation was then calculated between seasonally averaged fire danger and daily drought indices for each time scale. Correlations between drought index values and seasonal average fire-danger outputs were calculated beginning on the last day of each season (28 February, 31 May, 31 August, and 30 November) and then lagged daily (every 10 days for PDSI) out to the first day of each season. In this paper, we define "lag" as the time from the end of a timescale for a drought index to the end of the timescale for a fire danger output. For example, comparing a 3-month SPEI on June 1 to a summer-long ERC on August 31 represents a 91-day lag, as the end of the ERC period occurs 91 days after the end of the SPEI period. Daily lag analysis was done to find any lags associated with maximum correlations and to look for potential predictability of fire danger in antecedent drought conditions through drought index memory. First, the maximum correlations found were documented along with the associated drought index time scale (EDDI, SPEI, and SPI) and lag time in days. This answers the questions of which of the 17 different time scales are associated with maximum correlation. Second, the correlation at the start of each season ( 90 -day lag) was obtained along with the time scale that resulted in that greatest start of season correlation.

\subsection{Case Study: Tubbs Fire Evaporative Demand Decomposition}

On 9 October 2017 a series of large and destructive wildfires ignited in California north of the San Francisco Bay with rapid spread driven by a severe north wind event. The Tubbs Fire was the most destructive of these fires and resulted in 5636 structures destroyed and 22 fatalities [27]. Following the approach in Hobbins [42], anomalies in $\mathrm{E}_{0}$ were decomposed to provide the contribution from the anomaly in each of its four drivers (temperature, specific humidity, wind speed, and downwelling solar radiation). We used spatially-averaged $\mathrm{E}_{0}$ data from Sonoma County, California, at the 2-week time scale (14-day running sum) to identify the dominant drivers of $\mathrm{E}_{0}$ leading up to and during the Tubbs Fire.

\section{Results}

\subsection{Correlation Analysis}

An example for the Northern Sierra, California PSA using summer average 1000 fuel moisture (fm-1000) is presented in Figure 2 to guide the reader on the methods used to c-hr reate subsequent Figures 3-7 based on drought index time scale and lag. Maximum $R^{2}$ (mapped in Figure 3 ) for EDDI (Figure 2a) is 0.86 at a 3-month time scale (mapped in Figure 4) and a 33-day lag (mapped in Figure 5). Similarly, the maximum $\mathrm{R}^{2}$, associated time scale, and associated lag for SPEI (Figure 2b), and SPI (Figure 2c) were mapped spatially by PSA in Figure 3. The plume of higher correlations extending back from the end of August indicates drought index memory in relation to fire danger (fm-1000 in this case) and highlights potential predictability of the fire-danger outputs at the start of the season (1 June in this case). Start of season maximum $\mathrm{R}^{2}$ was 0.58 for EDDI (Figure 2a), 0.40 for SPEI (Figure 2b), and 0.34 for SPI (Figure 2c), and these are mapped spatially by PSA in Figure 6. Time scales associated with maximum start of season $\mathrm{R}^{2}$ were 6-month (December-May) for EDDI, 2-month (April-May) for SPEI, and 11-month (July-May) for SPI, and these are mapped spatially by PSA in Figure 7.

Maximum correlations between the four drought indices and seasonal fm-1000 (summarized results for ERC and 100-hr fuel are shown in Tables S1 and S2) are shown in Figure 3. Seasonally, only minor variations in $\mathrm{R}^{2}$ were found with spring showing the strongest relationships (domain mean $\mathrm{R}^{2}$; Table 1) for all drought indices. When considering CA-NV average $\mathrm{R}^{2}$ across all PSAs, the SPEI and EDDI consistently show the strongest relationships (with the exception of winter, when SPI had a greater $\mathrm{R}^{2}$ than EDDI) and often accounted for $>80 \%$ of the fm-1000 variance at individual PSAs, followed by SPI. PDSI demonstrated the weakest relationships across all seasons. 


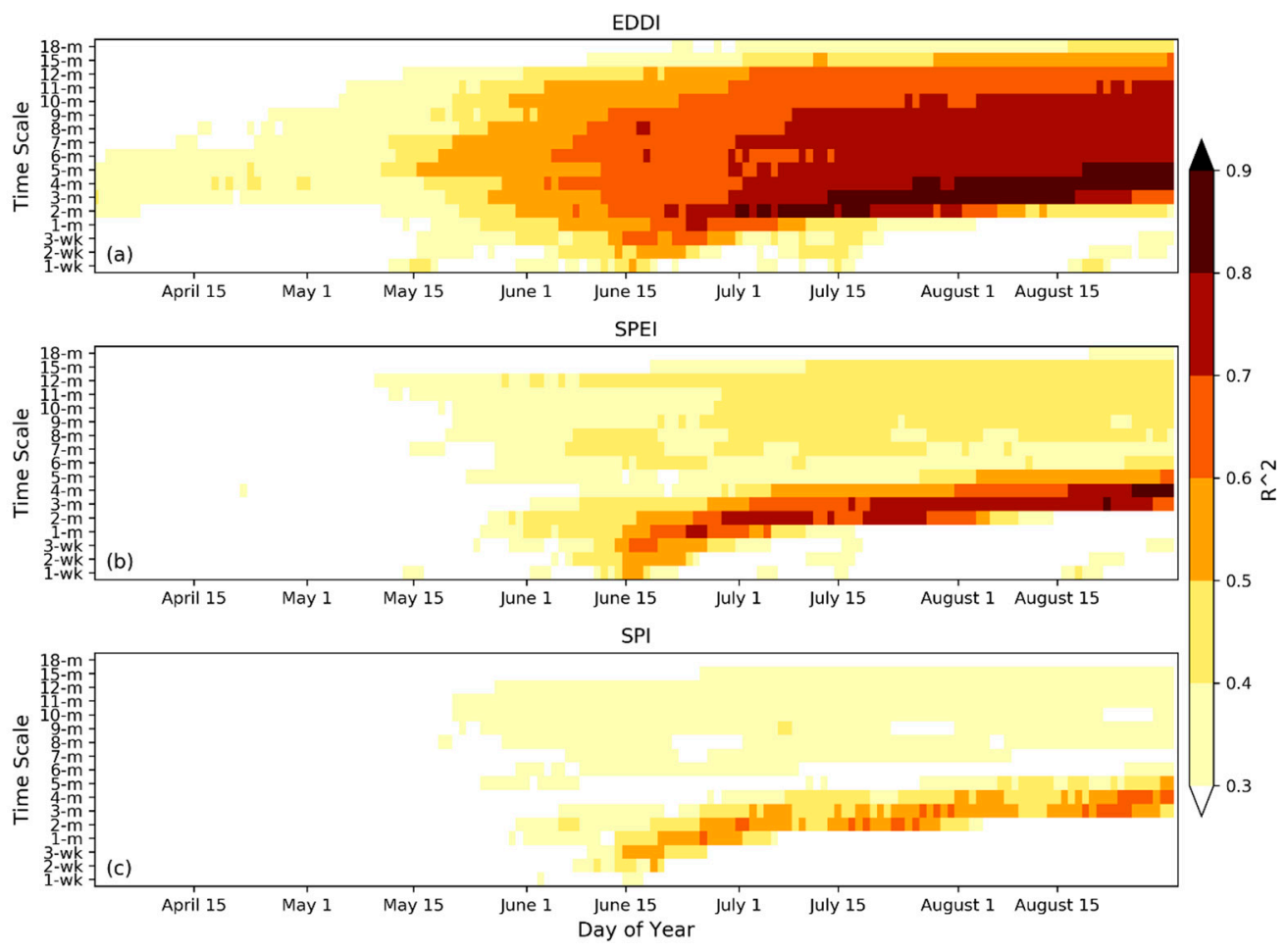

Figure 2. Average summer 1000-hr fuel moisture correlated to (a) the Evaporative Demand Drought Index (EDDI), (b) the Standardized Precipitation Evapotranspiration Index (SPEI), and (c) the Standardized Precipitation Index (SPI) at the Northern Sierra Nevada, California PSA. Vertical axis indicates drought index time scale in weeks (wk) or months $(\mathrm{m})$ and horizontal axis shows the drought index ending day for the correlation. The zero-day lag is indicated at 31 August and the start of season lag ( 90-day) is indicated at 1 June.

Overall, timescales of three to five months were most commonly associated with the maximum correlations (Figure 4). Substantial variability can be found at the PSA level and also between different indices and different seasons. For example, during the fall, maximum correlations mostly corresponded to 3- and 4-month time scales with EDDI (Figure 4d), but for SPEI (Figure 4e) maximum correlations at many PSAs in central and northern California corresponded to 5-month to 7-month timescales and to 2-month timescales in northern Nevada. In winter, maximum correlations corresponded to 8-month to 10-month timescales for SPEI (Figure 3h) and SPI (Figure 4i) in several central California and western Nevada PSAs.

Lag times associated with maximum correlations to fm-1000 (maximum correlations shown in Figure 3) are shown in Figure 5. Generally, lags of less than 10 days were found with some variability at the PSA level. Most notably lags of 50-60 days were found with EDDI, SPEI, and SPI during the summer (Figure $5 \mathrm{a}-\mathrm{c}$, respectively), lags of 40-50 days with SPI during fall (Figure 5g), and lags of 30-60 days with EDDI (Figure 5m), SPEI (southeast California and southern Nevada only; Figure 5n), SPI (southeast California only; Figure 5o), and PDSI (Lower Deserts PSA only; Figure 5p).

Daily lag correlations revealed that maximum correlations almost always occurred within the target season (lags < 90 days) and often close to the end of the target season (Figure 5). However, looking at the lag correlations matrices revealed substantial memory in the drought indices with strong correlations often beyond the 90-day lag (Figure 2). Figure 6 shows correlations for the 90-day (approximately one season) lag to highlight potential windows of seasonal fire danger predictability by drought indices. Summer showed the strongest correlations across the entire region with EDDI (Figure 6a; domain mean $R^{2}=0.50$, Table 1 ) and SPEI (Figure $6 \mathrm{~b}$; domain mean $\mathrm{R}^{2}=0.47$, Table 1 ) again most frequently having the highest $\mathrm{R}^{2}$. EDDI summer correlations were strongest in California with several PSAs above $0.6 R^{2}$ and a peak of 0.65 at the Upper Deserts PSA (Figure 6a). For SPEI in 
summer, the Northeast Nevada PSA had the strongest correlation with an $R^{2}$ of 0.63 , while $\mathrm{R}^{2}$ in most of central and northeast Nevada was above 0.5 (Figure 6b). Fairly strong relationships were also found in spring with EDDI (Figure 6m), SPEI (Figure 6n), and SPI (Figure 60), but limited primarily to the southernmost PSAs where several locations had $\mathrm{R}^{2}$ values between 0.5 and 0.69 . Winter (Figure 6i-1) and fall (Figure $6 \mathrm{e}-\mathrm{h}$ ) correlations were weak overall with the exception of a few PSAs where EDDI, SPEI, and SPI were able to explain about $30-40 \%$ of the seasonal fm- 1000 variability.

Timescales associated with maximum 90-day lag correlations are displayed in Figure 7. Overall, these timescales are much different than those shown in Figure 3, which primarily are associated with much shorter lags. Summer correlations corresponded mostly to longer time scales of 10-15 months for most PSAs. Notably shorter time scales were found in much of central and northern California for all three drought indices. For spring, the southern PSAs (where moderate correlations were found) time scales of maximum correlation were much shorter-mostly in the range of 1-3 months. Given the weak relationships found in fall and winter (Figure 6), little value or physical meaning should be given to the associated time scales.
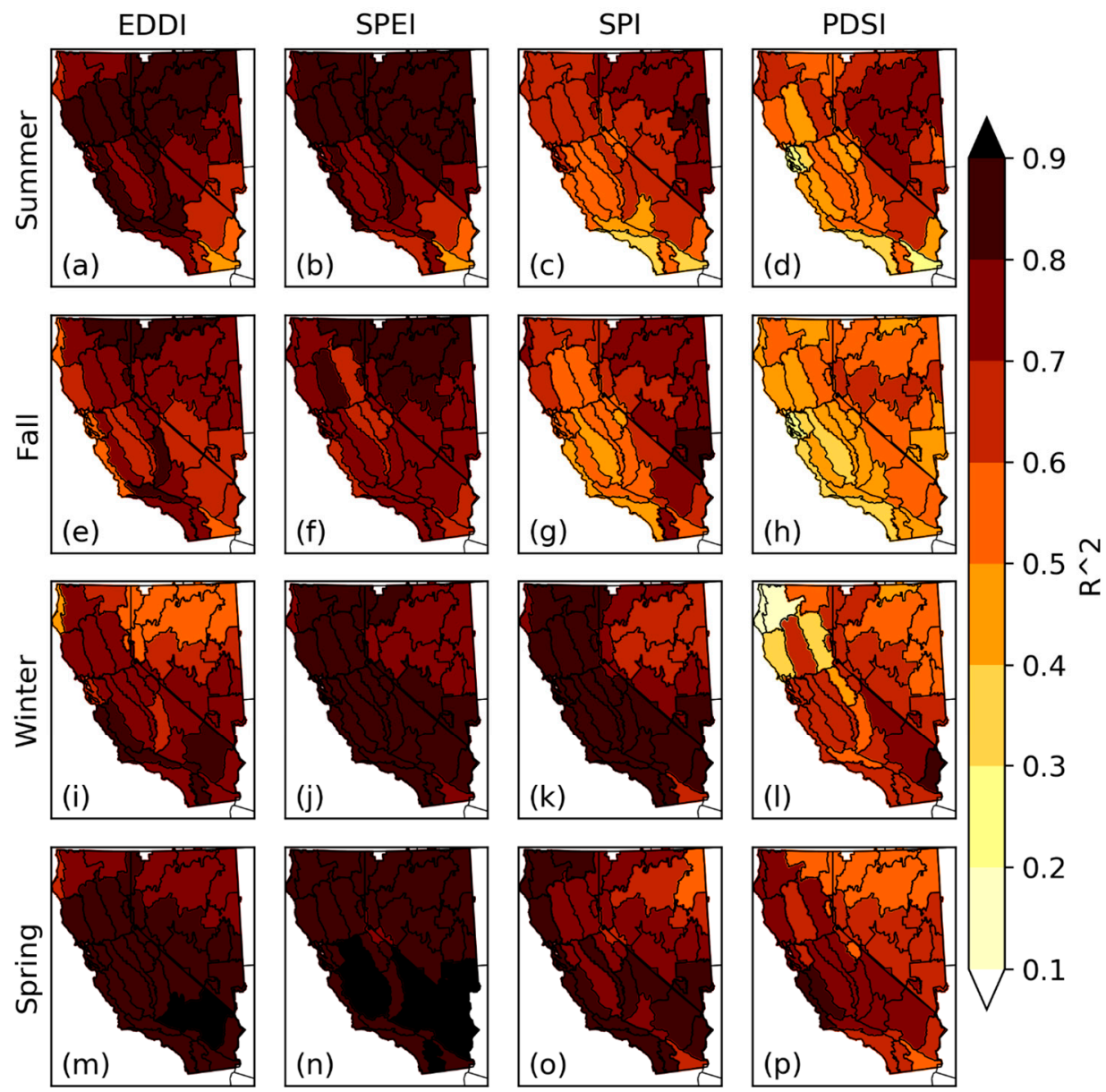

Figure 3. Maximum $\mathrm{R}^{2}$ of each drought index with the seasonal 1000-hr fuel moisture fire danger output by season across the period 1979-2015 for each PSA in California and Nevada. Drought indices include (a,e,i, $\mathbf{m})$ EDDI, $(\mathbf{b}, \mathbf{f}, \mathbf{j}, \mathbf{n})$ SPEI, (c, $, \mathbf{g}, \mathbf{k}, \mathbf{o})$ SPI, and $(\mathbf{d}, \mathbf{h}, \mathbf{l}, \mathbf{p})$ PDSI and seasons include $(\mathbf{a}, \mathbf{b}, \mathbf{c}, \mathbf{d})$ summer, (e,f, $\mathbf{g}, \mathbf{h})$ fall, $(\mathbf{i}, \mathbf{j}, \mathbf{k}, \mathbf{l})$ winter, and $(\mathbf{m}, \mathbf{n}, \mathbf{o}, \mathbf{p})$ spring. 
Table 1. California-Nevada domain-average maximum $R^{2}$ between seasonally averaged $\mathrm{fm}-1000$ and drought indices.

\begin{tabular}{ccc}
\hline & \multicolumn{2}{c}{ Maximum $\mathbf{R}^{\mathbf{2}}$} \\
& All Lags & 90-Day Lag \\
\hline Summer & & \\
EDDI & 0.78 & 0.5 \\
SPEI & 0.81 & 0.47 \\
SPI & 0.65 & 0.38 \\
PDSI & 0.59 & 0.32 \\
\hline Fall & & \\
EDDI & 0.73 & 0.23 \\
SPEI & 0.77 & 0.22 \\
SPI & 0.66 & 0.19 \\
PDSI & 0.5 & 0.11 \\
\hline Winter & & \\
EDDI & 0.7 & 0.28 \\
SPEI & 0.83 & 0.29 \\
SPI & 0.77 & 0.29 \\
PDSI & 0.59 & 0.08 \\
\hline Spring & & \\
EDDI & 0.83 & 0.32 \\
SPEI & 0.87 & 0.37 \\
SPI & 0.77 & 0.33 \\
PDSI & 0.66 & 0.21 \\
\hline
\end{tabular}
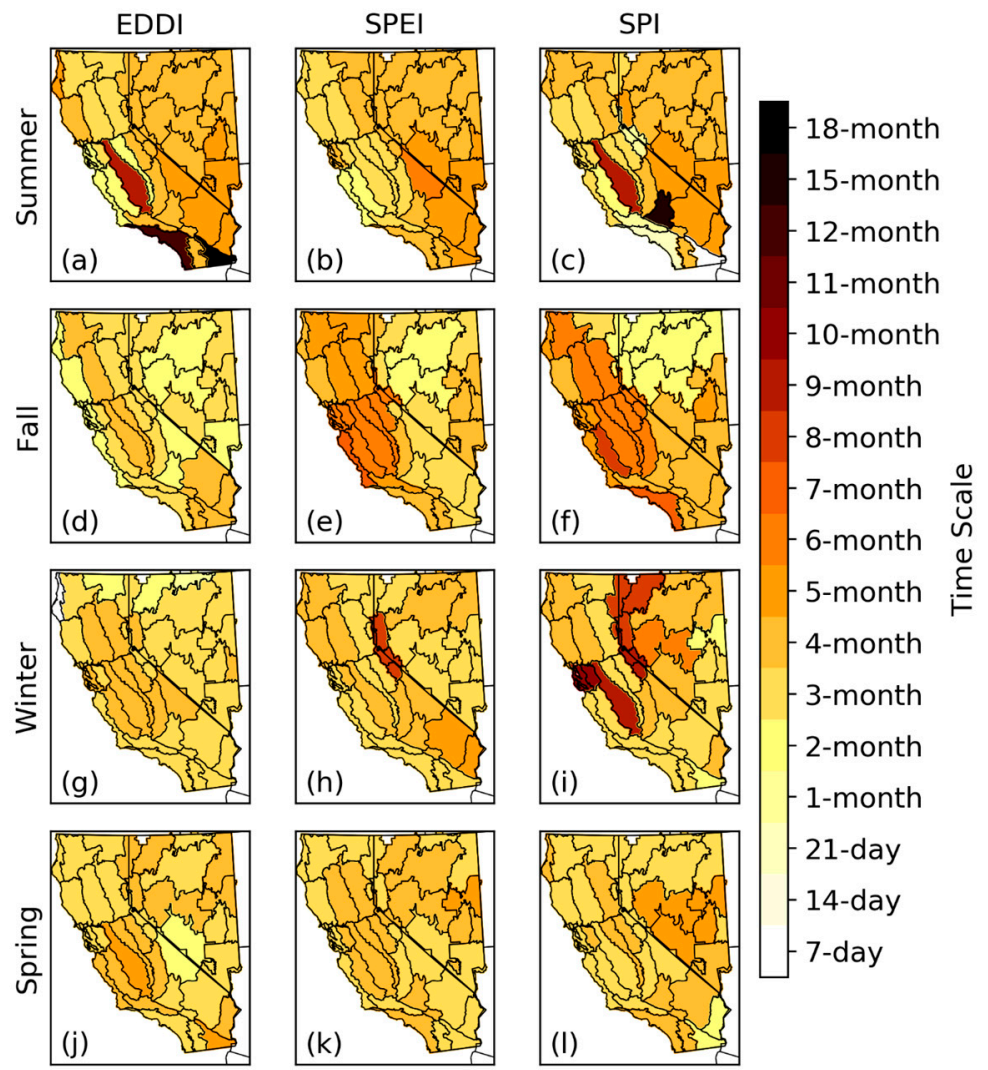

Figure 4. Time scale of each drought index associated with the maximum correlations shown in Figure 2. Drought indices include (a,d, $\mathbf{g}, \mathbf{j})$ EDDI, $(\mathbf{b}, \mathbf{e}, \mathbf{h}, \mathbf{k})$ SPEI, and $(\mathbf{c}, \mathbf{f}, \mathbf{i}, \mathbf{l})$ SPI, and seasons include $(\mathbf{a}, \mathbf{b}, \mathbf{c})$ summer, $(\mathbf{d}, \mathbf{e}, \mathbf{f})$ fall, $(\mathbf{g}, \mathbf{h}, \mathbf{i})$ winter, and $(\mathbf{j}, \mathbf{k}, \mathbf{l})$ spring. 

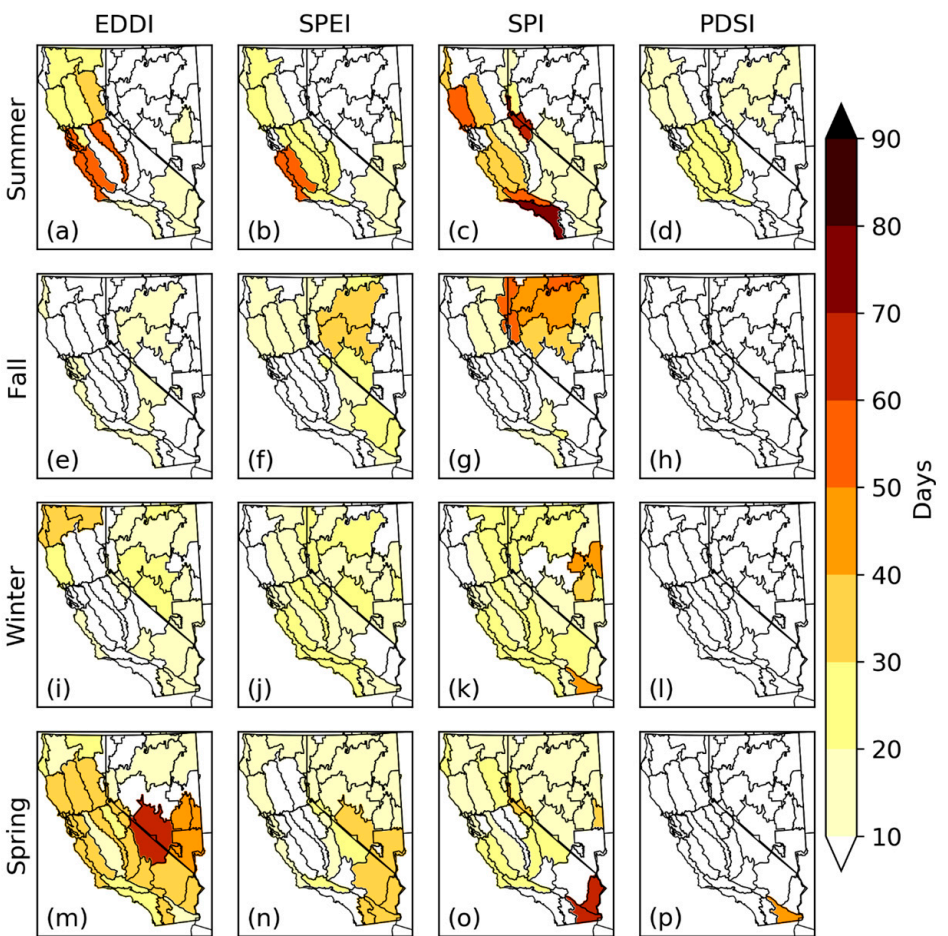

Figure 5. Lag (in days) at which the maximum correlation (highest $R^{2}$ ) is found between each of the four drought indices and the 1000-hr fuel moisture fire-danger output, broken down by season and by PSA across California and Nevada. Drought indices include $(\mathbf{a}, \mathbf{e}, \mathbf{i}, \mathbf{m})$ EDDI, $(\mathbf{b}, \mathbf{f}, \mathbf{j}, \mathbf{n})$ SPEI, $(\mathbf{c}, \mathbf{g}, \mathbf{k}, \mathbf{o})$ SPI, and $(\mathbf{d}, \mathbf{h}, \mathbf{l}, \mathbf{p})$ PDSI and seasons include $(\mathbf{a}, \mathbf{b}, \mathbf{c}, \mathbf{d})$ summer, $(\mathbf{e}, \mathbf{f}, \mathbf{g}, \mathbf{h})$ fall, $(\mathbf{i}, \mathbf{j}, \mathbf{k}, \mathbf{l})$ winter, and $(\mathbf{m}, \mathbf{n}, \mathbf{o}, \mathbf{p})$ spring.
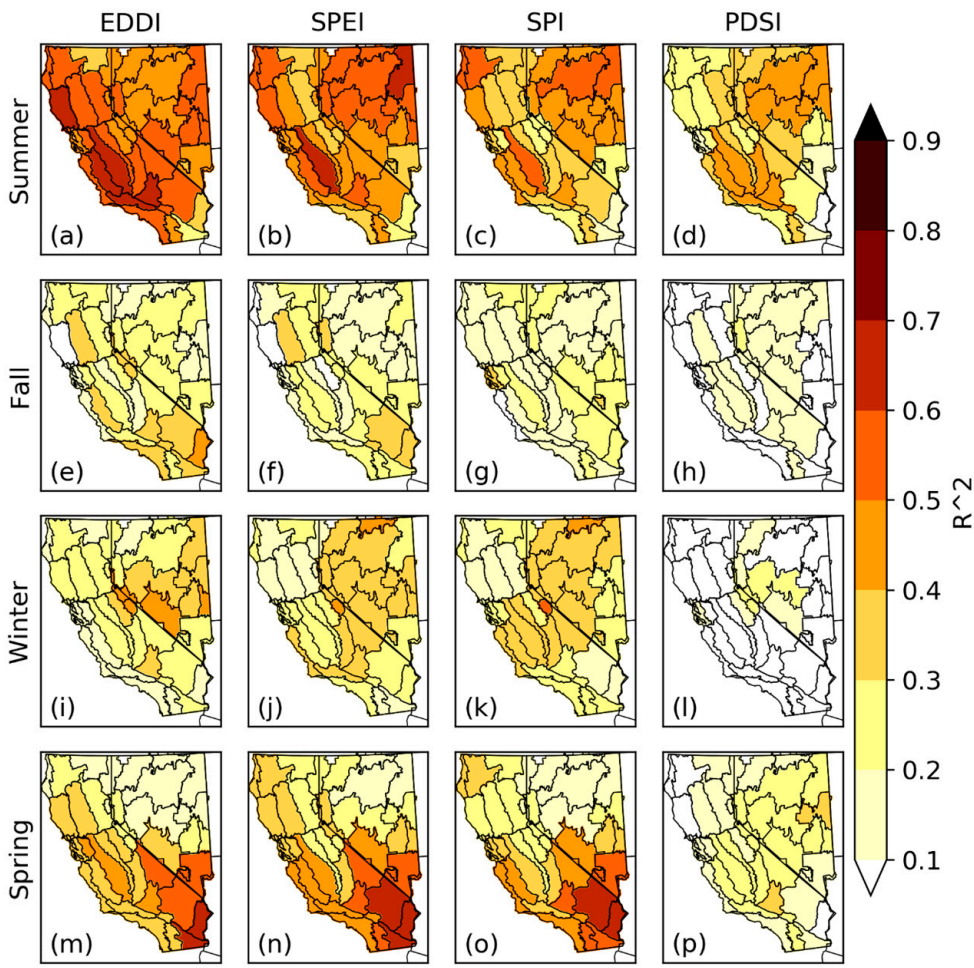

Figure 6. Start of season (90-day lag) $\mathrm{R}^{2}$ of each drought index with the seasonal 1000-hr fuel moisture fire danger output by season across the period 1979-2015 for each PSA in California and Nevada. Drought indices include (a,e,i,m) EDDI, $(\mathbf{b}, \mathbf{f}, \mathbf{j}, \mathbf{n})$ SPEI, $(\mathbf{c}, \mathbf{g}, \mathbf{k}, \mathbf{o})$ SPI, and $(\mathbf{d}, \mathbf{h}, \mathbf{l}, \mathbf{p})$ PDSI and seasons include (a,b,c,d) summer, (e,f,g,h) fall, $(\mathbf{i}, \mathbf{j}, \mathbf{k}, \mathbf{l}, \mathbf{l})$ winter, and $(\mathbf{m}, \mathbf{n}, \mathbf{o}, \mathbf{p})$ spring. 

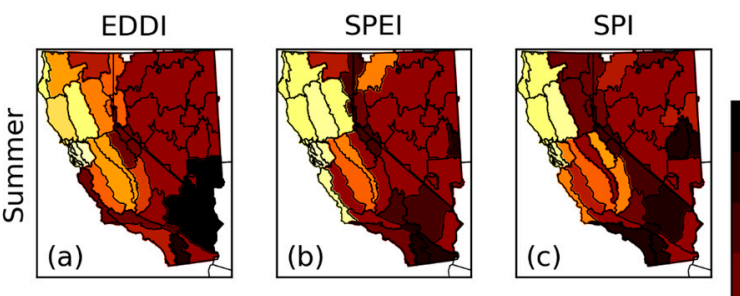

-18-month

15-month
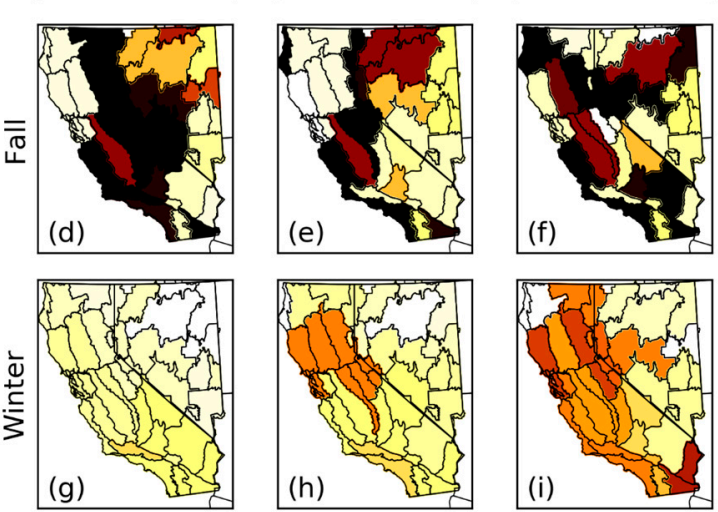

11-month
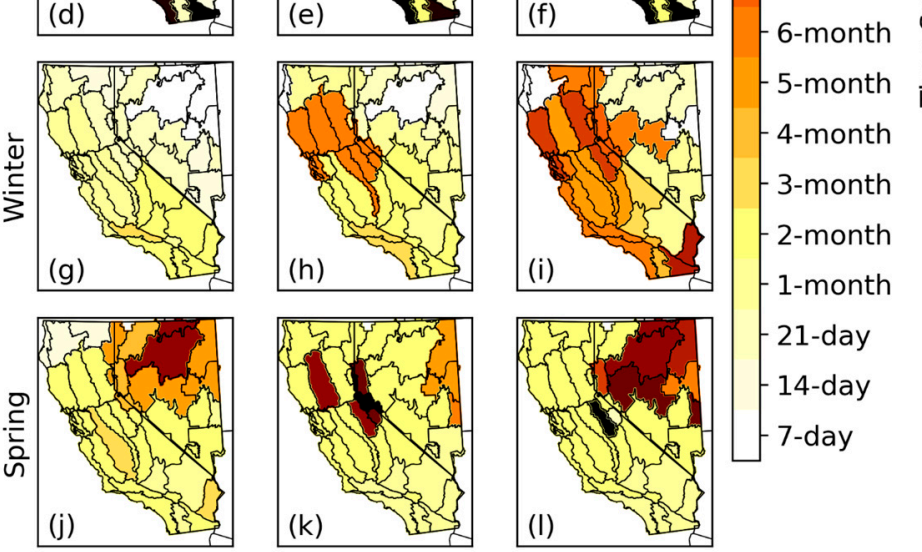

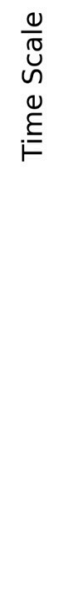

Figure 7. Time scale of each drought index associated with the 90-day lag correlations shown in Figure 5. Drought indices include (a,d, $\mathbf{g}, \mathbf{j})$ EDDI, (b,e, $\mathbf{h}, \mathbf{k})$ SPEI, and (c,f,i, $\mathbf{l})$ SPI, and seasons include $(\mathbf{a}, \mathbf{b}, \mathbf{c})$ summer, $(\mathbf{d}, \mathbf{e}, \mathbf{f})$ fall, $(\mathbf{g}, \mathbf{h}, \mathbf{i})$ winter, and $(\mathbf{j}, \mathbf{k}, \mathbf{l})$ spring.

\subsection{Evaporative Demand Attribution Leading Up to the Tubbs Fire}

To illustrate the relationship of the drivers of $E_{0}$ and developing fire potential, Figure 8 tracks the development of the $\mathrm{E}_{0}$ anomaly and the contributions from each of its drivers across Sonoma County, California from mid-August through the end of October, 2018, covering the period of eight weeks prior to three weeks following the ignition of the Tubbs Fire. To minimize the noise of day-to-day weather patterns, all variables are aggregated over a two-week window moving forward daily. $\mathrm{E}_{0}$ is elevated above its climatological mean throughout the period, with two notable spikes of $\mathrm{E}_{0}$ percentiles elevated above $90 \%$ for extended periods. The first spike occurred from 31 August until 5 September (prior to the fire outbreak): Its greatest early contribution was from above-normal temperatures, with the effects of the other drivers acting to mitigate the rise in $\mathrm{E}_{0}$ for at least part of the time-particularly humidity, which remained above normal. During the first two weeks of September, the above-normal temperatures abate, leading to a declining, though still positive, $\mathrm{E}_{0}$ anomaly. However, the mitigating effects of above-normal humidity and below-normal wind speeds and solar radiation all reverse during this period to leave $\mathrm{E}_{0}$ near normal for the second half of September. After this point, temperature remains near normal, but the combined effects of now-below-normal humidity and above-normal wind speed and solar radiation dominate the $\mathrm{E}_{0}$ anomaly, which climbs again through the day of the fire ignition (8 October) and afterwards. On the day of ignition, $\mathrm{E}_{0}$ reaches its second spike when it exceeds its 95th percentile. This indicates that near-surface moisture was decreasing and a drying of the air mass was taking place even during a period of temperatures declining to near-normal values. It is also worth noting that wind speed had the largest contributions during the onset of the second spike from 29 September through 2 October. These patterns are suggestive of an important role of rapid (flash) meteorological impacts on fuels. 


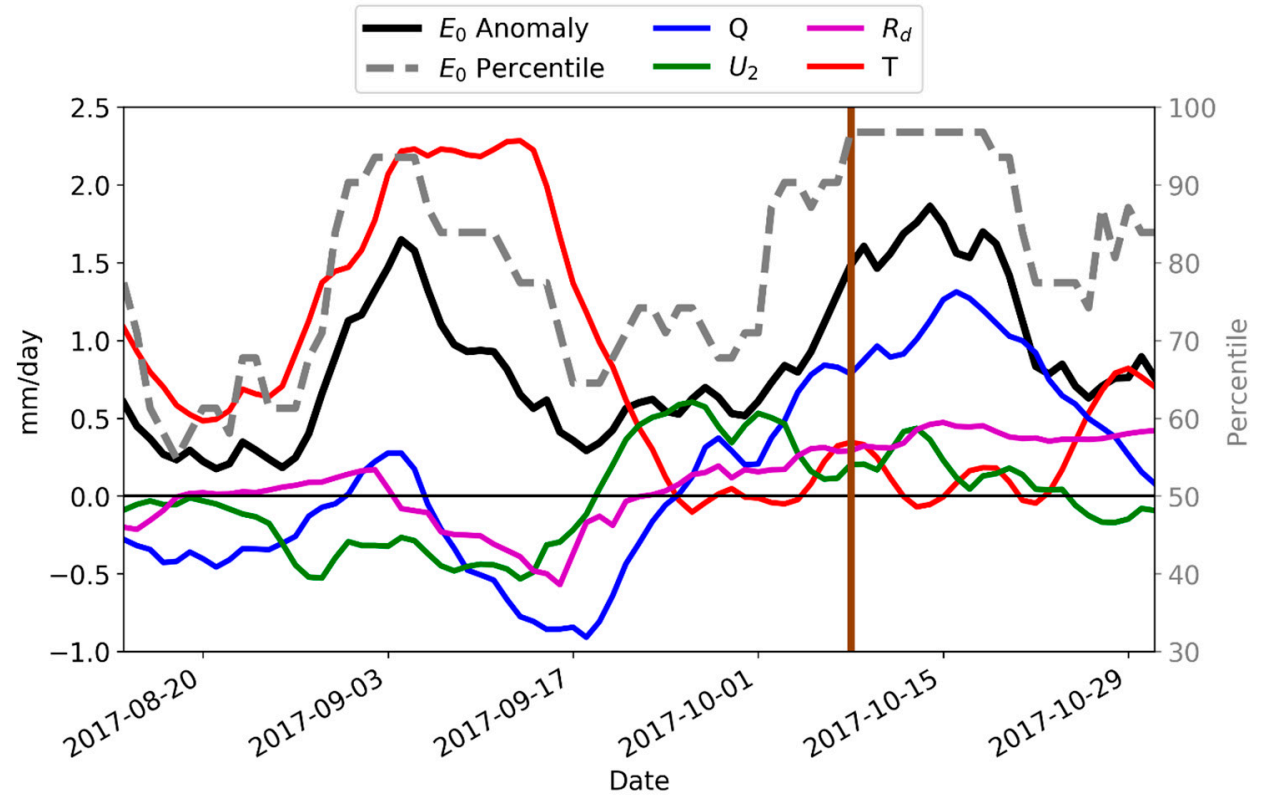

Figure 8. Attribution of evaporative demand $\left(E_{0}\right)$ anomaly prior to and during the Tubbs Fire in Sonoma County, California, into contributions from each of its meteorological and radiative drivers. The 2-week $E_{0}$ anomaly (black line) is spatially averaged across Sonoma County. The contributions from each of its drivers are shown as colored lines (temperature $(\mathrm{T})$ in red, specific humidity $(\mathrm{Q})$ in blue, downwelling shortwave radiation $\left(R_{d}\right)$ in purple, wind speed $\left(U_{2}\right)$ in green); percentiles of 2-week $\mathrm{E}_{0}$ are shown in dashed grey (right-hand axis); and the ignition date of the Tubbs Fire is shown as a vertical brown line.

\section{Discussion}

Findings from the maximum correlation analysis (Figure 3) demonstrate that the multi-scalar drought indices that incorporate $\mathrm{E}_{0}$ (EDDI and SPEI) typically have the strongest relationships to fire danger outputs. This is not a surprising finding given that fire danger outputs are computed with the same inputs as EDDI and SPEI, but it emphasizes an opportunity to take advantage of the multi-scalar features of EDDI and SPEI to incorporate antecedent drought information into fire management. That is, multi-scalar drought indices could serve to complement the existing NFDRS daily derived outputs. One exception to EDDI having the strongest relationships was winter, when SPI is better correlated than EDDI, which is most likely due to the fact that most of the annual precipitation in the region (especially in California) falls during the winter. Precipitation is much more limited during the warm-season months of April through September, and evaporative dynamics-driven by high temperatures, high wind, and low humidity—have a greater effect on drying of fuel moisture. The PDSI, which consistently showed the weakest relationships, also incorporates $\mathrm{E}_{0}$ but uses a much different model than EDDI and SPEI to depict drought, and has a static time scale of about 9-12 months that is clearly too long to reflect seasonal changes in fuel moisture.

Of the three fire danger outputs tested, the strongest correlations to drought indices were most often found with fm-1000, although in some cases, at the PSA and domanin average scale, fm-100 or ERC had stronger correlations. The fm-1000 inherently has some climate and drought memory, given the larger diameter vegetation (compared to fm-100) and the approximately 42 days (1000 hours) it takes the fuel particle to reach two thrids of the way to equilibrium with its local environment. However, all three fire danger outputs were averaged seasonally for this analysis, removing the higher frequency signals found in the daily ERC and fm-100, leading to stronger relationships with seasonal or longer drought time scales.

One application of drought indices that are strongly linked to fuel moisture is input for wildland fire outlooks. In the United States, Predictive Services issues monthly a National Significant Wildland 
Fire Potential Outlook [43] for fire management strategic planning and decision making. The drought index lag correlations described here offer potential for informing fire outlook products. This is most apparent in summer when EDDI and SPEI will likely provide the best results. A refinement of the correlations could be to develop statistical regression models at the PSA level based on the best combinations of drought indices to predict fuel moisture and fire potential. A combination of drought indices is suggested since large variability was found when looking at individual PSAs and there was not a single drought index "champion" for the entire region. A statistical model could help improve summer outlooks given the poor skill currently found in seasonal dynamical precipitation forecasts [44-47] and since precipitation plays only a minor role in fire danger during the summer in CA-NV. The connection between $\mathrm{E}_{0}$ and fire danger outputs also highlights the possibility of using seasonal $\mathrm{E}_{0}$ forecasts as a tool for fire potential, which have been shown to provide better skill than precipitation forecasts in the U.S. [47].

Results from the $\mathrm{E}_{0}$ attribution highlight the potential to use this method as a tool to monitor set-up conditions that are conducive to explosive fire growth and behavior, as was seen with the Tubbs Fire. Further examination of this methodology may show climatological signatures of fire weather in $\mathrm{E}_{0}$ and its drivers that are typical to a particular region and season; this may prove to be of predictive use to fire managers. Our correlation analysis focused on seasonal time scales, but the attribution example shows the potential for using $\mathrm{E}_{0}$ and EDDI as tools for guidance in short-term products such as the Predictive Services' 7-day Significant Fire Potential outlooks. Notably, the drying of the air mass that began in mid-September and the steady increase in specific humidity contributions (becoming the dominant driver several days before the fire began) to the $\mathrm{E}_{0}$ anomaly, combined with positive contributions from wind speed, could be seen as an early warning signal for increased fire potential when used in conjunction with many of the other indicators that were also signaling extreme fire potential in the days leading up to the Tubbs Fire [28]. One case study greatly limits the confidence in using this type of information for fire risk, and more work is needed looking at $\mathrm{E}_{0}$ and EDDI for prediction of short-term fire potential.

\section{Conclusions}

Strong relationships exist between all drought indices and fire danger outputs tested at all seasons and at most PSAs. Drought indices that incorporate $\mathrm{E}_{0}$ and are multi-scalar (i.e., EDDI and SPEI) typically were found to have the strongest correlations to fire danger outputs. This suggests that seasonally (3- to 4-month EDDI, SPEI, and SPI), more severe drought conditions will be coincident will dryer fuel moisture and greater fire danger. Some predictive potential exists for start of season fire potential outlooks using drought indices, but is restricted to summer (entire region) and spring (southern PSAs) with EDDI and SPEI providing the most value. Time scales associated with start of season lag correlations indicate that antecedent drought conditions from the previous fall and winter play a strong role in determining summer fuel moisture and fire danger in CA-NV.

To advance the understanding of and value added by using drought indices for fire management, real world testing and application is the next needed step. A partnership between Predictive Services in northern California and the team of researchers who conducted this study has been established, and beta-testing of EDDI as a management tool was performed during summer and fall of 2018. Initial feedback indicates that EDDI was useful in determining set-up conditions prior to the Carr Fire (23 July) near Redding, California, and Camp Fire (8 November) in Paradise, California $[48,49]$. Both fires were among the top 20 largest in California history and the Camp Fire was by far the most destructive in history with 85 deaths and nearly 19,000 structures destroyed [13]. Two specific applications of EDDI included using operational EDDI maps to replace the U.S. Drought Monitor (USDM) [50] in U.S. Forest Service Region 5 severity funding requests (requests are made throughout each fire season during periods with potential for abnormally severe fire behavior) and use of EDDI graphics in North Ops Predictive Services' seasonal fire potential outlooks. The USDM does not explicitly consider fire potential and was not designed to be used operationally by fire managers, but project stakeholders 
consistently pointed to using the USDM as the primary tool to assess drought conditions related to fire potential. This is largely due to lack of training or engagement describing proper tools that more accurately depict drought relationships to fire potential at various time scales. This project highlights a value of connecting drought researchers to the fire management community.

Several web-based applications have been developed recently that can provide continental U.S.-wide access to drought and fire danger outputs in near real-time, including the Google Earth Engine [51] cloud computing tool Climate Engine [52], the West Wide Drought Tracker [53], and NOAA's operational EDDI tools [54]. These tools can be used with guidance from this analysis and feedback from stakeholders to build the drought-fire connection capacity in the CA-NV DEWS. Further studies in other regions, more research linking short-term drought (i.e., sub-monthly drought index time scales) to real-time fire potential (i.e., flash drying of fuels) and behavior, and applied stakeholder testing outside of northern California is needed and encouraged to successfully expand the application of drought information for operational fire management purposes.

Supplementary Materials: The following are available online at http:/ / www.mdpi.com/2225-1154/7/4/52/s1, Table S1: California-Nevada domain-average maximum $\mathrm{R}^{2}$ between seasonally averaged 1000-hr fuel moisture and drought indices, Table S2: California-Nevada domain-average maximum $\mathrm{R}^{2}$ between seasonally averaged 1000-hr fuel moisture and drought indices.

Author Contributions: Conceptualization, D.J.M., T.J.B., and T.W.; Data Analysis and Visualizations, D.J.M. and M.H.; Writing, Reviewing, and Editing, D.J.M., M.H., T.J.B., K.V., T.W., J.L.H., and M.S.; Stakeholder Engagement, D.J.M., T.J.B., K.V., and T.W.

Funding: Funding for the work was provided by the National Oceanic and Atmospheric Administration and National Integrated Drought Information System (NIDIS) Sectoral Applications Research Program grant \#NA16OAR4310128 and NIDIS California-Nevada Drought Early Warning System grant \#AB-133E-16-cQ-0022.

Conflicts of Interest: The authors declare no conflict of interest.

\section{References}

1. Swetnam, T.W.; Betancourt, J.L. Fire-Southern Oscillation relations in the southwestern United States. Science 1990, 249, 1017-1020. [CrossRef] [PubMed]

2. Bessie, W.C.; Johnson, E.A. The relative importance of fuels and weather on fire behavior in subalpine forests. Ecology 1995, 76, 747-762. [CrossRef]

3. Westerling, A.L.; Brown, T.J.; Gershunov, A.; Cayan, D.R.; Dettinger, M.D. Climate and wildfire in the western United States. Bull. Am. Meteorol. Soc. 2003, 84, 595-604. [CrossRef]

4. Littell, J.S.; McKenzie, D.; Peterson, D.L.; Westerling, A.L. Climate and wildfire area burned in western US ecoprovinces, 1916-2003. Ecol. Appl. 2009, 19, 1003-1021. [CrossRef] [PubMed]

5. Riley, K.L.; Abatzoglou, J.T.; Grenfell, I.C.; Klene, A.E.; Heinsch, F.A. The relationship of large fire occurrence with drought and fire danger indices in the western USA, 1984-2008: The role of temporal scale. Int. J. Wildland Fire 2013, 22, 894-909. [CrossRef]

6. Prein, A.F.; Holland, G.J.; Rasmussen, R.M.; Clark, M.P.; Tye, M.R. Running dry: The US Southwest's drift into a drier climate state. Geophys. Res. Lett. 2016, 43, 1272-1279. [CrossRef]

7. Dennison, P.E.; Brewer, S.C.; Arnold, J.D.; Moritz, M.A. Large wildfire trends in the western United States, 1984-2011. Geophys. Res. Lett. 2014, 41, 2928-2933. [CrossRef]

8. Griffin, D.; Anchukaitis, K.J. How unusual is the 2012-2014 California drought? Geophys. Res. Lett. 2014, 41, 9017-9023. [CrossRef]

9. Hatchett, B.J.; Boyle, D.P.; Putnam, A.E.; Bassett, S.D. Placing the 2012-2015 California-Nevada drought into a paleoclimatic context: Insights from Walker Lake, California-Nevada, USA. Geophys. Res. Lett. 2015, 42, 8632-8640. [CrossRef]

10. Robeson, S.M. Revisiting the recent California drought as an extreme value. Geophys. Res. Lett. 2015, 42, 6771-6779. [CrossRef]

11. Shukla, S.; Safeeq, M.; AghaKouchak, A.; Guan, K.; Funk, C. Temperature impacts on the water year 2014 drought in California. Geophys. Res. Lett. 2015, 42, 4384-4393. [CrossRef] 
12. Williams, A.P.; Seager, R.; Abatzoglou, J.T.; Cook, B.I.; Smerdon, J.E.; Cook, E.R. Contribution of anthropogenic warming to California drought during 2012-2014. Geophys. Res. Lett. 2015, 42, 6819-6828. [CrossRef]

13. Cal Fire Top 20 Largest California Wildfires. Available online: https://www.fire.ca.gov / communications / downloads / fact_sheets/Top20_Acres.pdf (accessed on 27 December 2018).

14. Keeley, J.E.; Safford, H.; Fotheringham, C.J.; Franklin, J.; Moritz, M. The 2007 southern California wildfires: Lessons in complexity. J. For. 2009, 107, 287-296.

15. Brown, J.F.; Wardlow, B.D.; Tadesse, T.; Hayes, M.J.; Reed, B.C. The Vegetation Drought Response Index (VegDRI): A new integrated approach for monitoring drought stress in vegetation. GISci. Remote Sens. 2008, 45, 16-46. [CrossRef]

16. Sohrabi, M.M.; Ryu, J.H.; Abatzoglou, J.T.; Tracy, J. Development of soil moisture drought index to characterize droughts. J. Hydrol. Eng. 2015, 20, 04015025. [CrossRef]

17. Carrão, H.; Russo, S.; Sepulcre-Canto, G.; Barbosa, P. An empirical standardized soil moisture index for agricultural drought assessment from remotely sensed data. Int. J. Appl. Earth Obs. 2016, 48, 74-84. [CrossRef]

18. Anderson, M.C.; Norman, J.M.; Mecikalski, J.R.; Otkin, J.A.; Kustas, W.P. A climatological study of evapotranspiration and moisture stress across the continental United States based on thermal remote sensing: 2. Surface moisture climatology. J. Geophys. Res.-Atmos. 2007, 112. [CrossRef]

19. Vicente-Serrano, S.M.; Beguería, S.; López-Moreno, J.I. A multiscalar drought index sensitive to global warming: The standardized precipitation evapotranspiration index. J. Clim. 2010, 23, 1696-1718. [CrossRef]

20. Hobbins, M.T.; Wood, A.W.; McEvoy, D.J.; Huntington, J.L.; Morton, C.; Anderson, M.C.; Hain, C.R. The Evaporative Demand Drought Index: Part I—Linking drought evolution to variations in evaporative demand. J. Hydrometeorol. 2016, 17, 1745-1761. [CrossRef]

21. McEvoy, D.J.; Huntington, J.L.; Hobbins, M.T.; Wood, A.W.; Morton, C.; Anderson, M.C.; Hain, C.R. The Evaporative Demand Drought Index: Part II-CONUS-wide assessment against common drought indicators. J. Hydrometeorol. 2016, 17, 1763-1779. [CrossRef]

22. Abatzoglou, J.T.; Kolden, C.A. Relationships between climate and macroscale area burned in the western United States. Int. J. Wildland Fire 2013, 22, 1003-1020. [CrossRef]

23. Predictive Services website. Available online: https://www.predictiveservices.nifc.gov (accessed on 4 February 2019).

24. Pulwarty, R.; Verdin, J.P. Crafting early warning systems: The case of drought. In Measuring Vulnerability to Natural Hazards: Towards Disaster Resilient Societies; Birkmann, J., Ed.; United Nations University Press: Tokyo, Japan, 2013.

25. Eidenshink, J.; Schwind, B.; Brewer, K.; Zhu, Z.L.; Quayle, B.; Howard, S. A project for monitoring trends in burn severity. Fire Ecol. 2007, 3, 3-21. [CrossRef]

26. Balch, J.; Schoennagel, T.; Williams, A.; Abatzoglou, J.; Cattau, M.; Mietkiewicz, N.; St Denis, L. Switching on the Big Burn of 2017. Fire 2018, 1, 17. [CrossRef]

27. Nauslar, N.; Abatzoglou, J.; Marsh, P. The 2017 North Bay and Southern California Fires: A Case Study. Fire 2018, 1, 18. [CrossRef]

28. Abatzoglou, J.T. Development of gridded surface meteorological data for ecological applications and modelling. Int. J. Climatol. 2013, 33, 121-131. [CrossRef]

29. Palmer, C.P. Meteorological drought. In US Weather Bureau Research Paper; US Weather Bureau: Silver Spring, MD, USA, 1965; Volume 45.

30. Heim, R.R. Computing the monthly Palmer Drought Index on a weekly basis: A case study comparing data estimation techniques. Geophys. Res. Lett. 2005, 32. [CrossRef]

31. Allen, R.G.; Walter, I.A.; Elliott, R.; Howell, T.; Itenfisu, D.; Jensen, M. The ASCE Standardized Reference Evapotranspiration Equation; American Society of Civil Engineers: Reston, VA, USA, 2005; p. 59.

32. McKee, T.B.; Doesken, N.J.; Kleist, J. The relationship of drought frequency and duration to time scales. In Proceedings of the American Meteorological Society, Boston, MA, USA, 17-22 January 1993; Volume 17, pp. 179-183.

33. Ford, T.W.; Labosier, C.F. Meteorological conditions associated with the onset of flash drought in the eastern United States. Agric. For. Meteorol. 2017, 247, 414-423. [CrossRef] 
34. Otkin, J.; Svoboda, M.D.; Hunt, E.; Ford, T.; Anderson, M.; Hain, C.R.; Basara, J. Flash droughts: A review and assessment of the challenges imposed by rapid onset droughts in the United States. Bull. Am. Meteorol. Soc. 2017, 99, 911-919. [CrossRef]

35. Lorenzo-Lacruz, J.; Vicente-Serrano, S.M.; López-Moreno, J.I.; Beguería, S.; García-Ruiz, J.M.; Cuadrat, J.M. The impact of droughts and water management on various hydrological systems in the headwaters of the Tagus River (central Spain). J. Hydrol. 2010, 386, 13-26. [CrossRef]

36. McEvoy, D.J.; Huntington, J.L.; Abatzoglou, J.T.; Edwards, L. An evaluation of multi-scalar drought indices in Nevada and eastern California. Earth Interact. 2012, 16, 1-18. [CrossRef]

37. Abatzoglou, J.T.; Barbero, R.; Wolf, J.; Holden, Z. Tracking interannual streamflow variability with drought indices in the U.S. Pacific Northwest. J. Hydrometeorol. 2014, 15, 1900-1912. [CrossRef]

38. Vicente-Serrano, S.M.; Beguería, S.; Lorenzo-Lacruz, J.; Camarero, J.J.; López-Moreno, J.I.; Azorin-Molina, C.; Sanchez-Lorenzo, A. Performance of drought indices for ecological, agricultural, and hydrological applications. Earth Interact. 2012, 16, 1-27. [CrossRef]

39. Hao, Z.; AghaKouchak, A. A nonparametric multivariate multi-index drought monitoring framework. J. Hydrometeorol. 2014, 15, 89-101. [CrossRef]

40. Farahmand, A.; AghaKouchak, A. A generalized framework for deriving nonparametric standardized drought indicators. Adv. Water Resour. 2015, 76, 140-145. [CrossRef]

41. Deeming, J.E.; Burgan, R.E.; Cohen, J.D. The National Fire Danger Rating System-1978; General Technical Report INT-39; USDA Forest Service, Intermountain Forest and Range Experiment Station: Ogden, UT, USA, 1977.

42. Hobbins, M.T. The variability of ASCE Standardized Reference Evapotranspiration: A rigorous, CONUS-wide decomposition and attribution. Trans. ASABE 2016, 59, 561-576.

43. Garfin, G.M.; Brown, T.J.; Wordell, T.; Delgado, E. The making of national seasonal wildfire outlooks. In Climate in Context: Science and Society Partnering for Adaptation; Parris, A.S., Garfin, G.M., Dow, K., Meyer, R., Close, S.L., Eds.; John Wiley and Sons Ltd.: West Sussex, UK, 2016; Volume 1, pp. 143-172.

44. Yuan, X.; Wood, E.F.; Roundy, J.K.; Pan, M. CFSv2-based seasonal hydroclimatic forecasts over the conterminous United States. J. Hydrometeorol. 2013, 26, 4828-4847. [CrossRef]

45. Saha, S.; Moorthi, S.; Wu, X.; Wang, J.; Nadiga, S.; Tripp, P.; Behringer, D.; Hou, Y.T.; Chuang, H.Y.; Iredell, M.; et al. The NCEP Climate Forecast System Version 2. J. Clim. 2014, 27, 2185-2208. [CrossRef]

46. Wood, E.; Schubert, S.; Wood, A.; Peters-Lidard, C.; Mo, K.; Mariotti, A.; Pulwarty, R. Prospects for advancing drought understanding, monitoring and prediction. J. Hydrometeorol. 2015, 16, 1636-1657. [CrossRef]

47. McEvoy, D.J.; Huntington, J.L.; Mejia, J.F.; Hobbins, M.T. Improved seasonal drought forecasts using reference evapotranspiration anomalies. Geophys. Res. Lett. 2016, 43, 377-385. [CrossRef]

48. Wachter, B.; (National Weather Service, Predictive Services, Redding, California, United States). Personal communication, 2018.

49. Wachter, B.; Applied EDDI. FIRESCOPE Fall Meeting, San Diego, California, 8 November 2018. Available online: https:/ / drive.google.com/file/d/1X-efCp6UDPlMj11W55m1MfinvYsKPA_S/view?usp=sharing (accessed on 4 February 2019).

50. Svoboda, M.; LeComte, D.; Hayes, M.; Heim, R.; Gleason, K.; Angel, J.; Rippey, B.; Tinker, R.; Palecki, M.; Stooksbury, D.; et al. The drought monitor. Bull. Am. Meteorol. Soc. 2002, 83, 1181-1190. [CrossRef]

51. Gorelick, N.; Hancher, M.; Dixon, M.; Ilyushchenko, S.; Thau, D.; Moore, R. Google Earth Engine: Planetary-scale geospatial analysis for everyone. Remote Sens. Environ. 2017, 202, 18-27. [CrossRef]

52. Huntington, J.L.; Hegewisch, K.C.; Daudert, B.; Morton, C.G.; Abatzoglou, J.T.; McEvoy, D.J.; Erickson, T. Climate Engine: Cloud computing and visualization of climate and remote sensing data for advanced natural resource monitoring and process understanding. Bull. Am. Meteorol. Soc. 2017, 98, 2397-2410. [CrossRef]

53. Abatzoglou, J.T.; McEvoy, D.J.; Redmond, K.T. The west wide drought tracker: Drought monitoring at fine spatial scales. Bull. Am. Meteorol. Soc. 2017, 98, 1815-1820. [CrossRef]

54. Evaporative Demand Drought Index Website. Available online: https://www.esrl.noaa.gov/psd/eddi/ (accessed on 4 February 2019).

(C) 2019 by the authors. Licensee MDPI, Basel, Switzerland. This article is an open access article distributed under the terms and conditions of the Creative Commons Attribution (CC BY) license (http:/ / creativecommons.org/licenses/by/4.0/). 